\title{
Pulmonary Vascular Disorder
}

National Cancer Institute

\section{Source}

National Cancer Institute. Pulmonary Vascular Disorder. NCI Thesaurus. Code C35531.

A category of non-neoplastic disorders that affect the blood vessels in the lungs.

Representative examples include pulmonary embolism, pulmonary hypertension, and arteriovenous malformations. 